\title{
Kirchenbau und Erinnerung in Rom unter Anaklet II. und Innozenz II.
}

\section{Sible de Blaauw}

Im Februar 1130 wurden in Rom zwei Päpste gewählt. Die Hoffnung, die Zeit der dramatischen Schismen und des Investiturstreits sei überwunden, währte damit nur kurz. Die politische Konstellation war jetzt zwar eine andere als vorher: nicht der Kaiser, sondern das zerstrittene Kardinalskollegium verursachte die Doppelwahl konkurrierender Pontifices, aber das Trauma der Schismen der jüngsten Vergangenheit muss die Stimmung nach den Papswahlen 1130 weitgehend beherrscht haben. Die Fakten des Überraschungscoups unter der Ägide des Kanzlers Haimerich und der Mehrheitswahl für Petrus Pierleoni sind größtenteils bekannt. Sie werden heute kaum mehr als ideologisch determiniert betrachtet. ${ }^{1}$ Über die Persönlichkeiten der beiden Gewählten, Innozenz II. Papareschi und Anaklet II. Pierleoni, die acht Jahre lang einander gegenüber standen, müssen jedoch viele Fragen unbeantwortet bleiben. ${ }^{2}$ Allerdings äußerte Gregorovius sich auf Grund seiner historischen Intuition - die sich häufig bewährt hat - über den ,Gegenpapst': „Dies ist sicher, dass der Kardinal Pierleoni nicht nur durch seinen Reichtum und seine Familienverbindungen, sondern auch durch seine geniale Persönlichkeit der größte Mann in Rom war..". ${ }^{3}$ Palumbo betont Anaklets Verwandtschaft in Geist und Charakter mit Calixt II. (1119-1124): "nella prudenza e nel decoro, tendente alla fastosità e alla munificenza“. ${ }^{4}$ Immerhin hinterlässt derjenige, den die Geschichte nachträglich als Gegenpapst abstempelt, üblicherweise die meisten Rätsel. ${ }^{5}$ Deswegen bleiben die Jahre der Herrschaft Anaklets II. über die Stadt Rom praktisch ein blinder Fleck in der Stadtgeschichte.

Das Schisma von 1130-1138 entzweite Europa, aber nicht die Papststadt. Rom stand zum größten Teil auf der Seite Anaklets. Petrus Pierleoni konnte fast acht Jahre lang in seiner Geburtsstadt das Papstamt ausüben, länger als die meisten Päpste seines Jahrhunderts. Während sich Innozenz - auch gebürtiger Römer - vornehmlich in Frankreich und Oberitalien aufhielt, konnte Anaklet sich nahezu ununterbrochen in Rom behaupten. ${ }^{6}$ Doch wissen wir kaum, was er in diesen Jahren bewirkt hat.

\footnotetext{
${ }^{1}$ Werner MALECZEK, Das Kardinalskollegium unter Innocenz II. und Anaklet II., Archivum historiae pontificiae 19 (1981), S. 327-378, S. 28-34; Timothy REUTER, Zur Anerkennung Papst Innocenz' II: eine neue Quelle, Deutsches Archiv 39 (1983), S. 395-416.

${ }^{2}$ Die ausführlichsten Abhandlungen über die Person und das Pontifikat des Anaklet sind Pier Fausto PALUMBO, Lo scisma del 1130: i precedenti, la vicenda romana e le ripercussioni europee della lotta tra Anacleto e Innocenzo II. Col regesto degli atti di Anacleto II., (Miscellanea della R. Deputazione romana di storia patria 13), Roma 1942 und Mary StRolL, The Jewish Pope: Ideology and Politics in the Papal Schism of 1130, Leiden - New York - Copenhagen 1987. Über das Kardinalskollegium des Anaklet: MALECZEK, (wie Anm. 2), S. 73-78.

${ }^{3}$ Ferdinand Gregorovius, Geschichte der Stadt Rom im Mittelalter. W. KAMPF (Hg.), 7 Bde., Darmstadt 1978. Bd. 2, S. 180

${ }^{4}$ PALUMBo (wie Anm. 2), S. 51, S. 369.

${ }^{5}$ Kai Michael SPREngeR, Damnatio Memoriae oder Damnatio in Memoria? Überlegungen zum Umgang mit so genannten Gegenpäpsten als methodisches Problem der Papstgeschichtsschreibung, Quellen und Forschungen aus italienischen Archiven und Bibliotheken 89 (2009), S. 31-62, bes. S. 49-55.

${ }^{6}$ Historia Compostellana 3.23.1, S. 454 (retrospektiv): electum [Innocentius] a civitate eiecit et in sede apostolica [Anacletus] quasi Papa remansit. Von den früheren,Gegenpäpsten' ist vielleicht nur die dauerhafte stadtrömische Obödienz Wiberts von Ravenna / Clemens III. vergleichbar. Wibert war jedoch
} 
Petrus Pierleoni stammte aus einer stolzen römischen Familie, die schon ein Jahrhundert lang auch städtebaulich in der Stadt präsent gewesen war; er war ein hochgebildeter Mann der Kirchenreform in der kunstfreudigen Tradition von Cluny; und last but not least: seine Macht als Papst stützte sich auf seine eigene Stadt, die unzählige kaiserliche und päpstliche Herrscher vor ihm immer wieder mit neuen Denkmälern bereichert hatten. Alle diese Elemente wären die natürliche und ideale Grundlage für ein fruchtbares Mäzenat gewesen, das vielleicht politisch sogar als Verfestigungsinstrument der Legitimität unentbehrlich war. Doch ist keine einzige Baumassnahme von Anaklet in den Quellen erwähnt oder in der Bausubstanz sichtbar geblieben. Sein Anhänger Pandulf hat wahrscheinlich eine Vita des Anaklet für seine Kontinuation des römischen Liber Pontificalis verfasst, die jedoch nicht erhalten ist. ${ }^{7}$ Die Version Pandulfs wurde in der Überlieferung von einer späteren, ausgesprochen Innozenz-freundlichen Fassung des Kardinals Boso verdrängt. So ist von der traditionellen Quelle für das päpstliche Stiftertum in diesem Punkt nichts zu erwarten.

Die Frage, die hier zur Diskussion steht, ist in wieweit Anaklet seine Herrschaft über Rom zur Legitimierung seiner Papstwahl nutzte. Die Frage ist häufiger gestellt worden, soll hier aber etwas spezifischer behandelt werden, nämlich in der Perspektive des Erinnerungspotenzials der Stadt. Dabei stellt sich das Problem, dass die von Anaklet aktivierten Erinnerungen angesichts der Identität der Stadt und des päpstlichen Amtes erwartungsgemäß aus dem späteren Überlieferungsrepertoire ausgelöscht worden sind. Deswegen richtet sich die Aufmerksamkeit dieser Darstellung auf die konkreten Erinnerungsträger: die stadtrömischen Kirchen, die der Papst traditionell als Zelebrans, Hüter und Mäzen nutzte und betreute. Hierin liegt eventuell eine Möglichkeit, das Problem der einseitigen Quellenlage teilweise zu kompensieren. Wie bei allen 'verlierenden Parteien' in der Geschichte ist auch im Falle Anaklets fast nur die Sichtweise der Gegner schriftlich tradiert worden. Abgesehen von vereinzelten Akten aus der Kanzlei Anaklets haben praktisch nur chronikartige Schriften mit einem ausgesprochenen Standpunkt gegen Pierleoni einen beständigen Weg in die Überlieferung gefunden. ${ }^{8}$ Infolgedessen sind fast alle Studien über Anaklet auf Herleitungen ex negativo aufgebaut. Doch auch die gebauten Denkmäler sind Quellen und als solche zu befragen.

\section{Anaklet und die Geschichte des Papsttums}

Fragen wir zunächst, welche Erinnerungen Petrus Pierleoni nach seiner Papstwahl selber aktivierte. Als programmatisch darf seine bemerkenswerte Namenswahl gelten. Sie greift auf die Anfänge der christlichen Kirche in Rom zurück. Seit dem 11. Jh. gab es eine Reihe von Päpsten, die einen Namen aus der fernen Vergangenheit wieder aufnahmen, wie Silvester II. und Damasus II. Es ging jedoch fast immer um Papstnamen aus den Jahrhunderten nach der konstantinischen Wende, das heißt, aus der Zeit, als die Bischöfe Roms schon einen höheren Rang als nur lokale Oberhirten innehatten und

selber kein Römer: Jürgen ZIESE, J. Wibert von Ravenna, der Gegenpapst Clemens III. (1084-1100), (Päpste und Papsttum 20), Stuttgart 1982, S. 99-107, S. 191-192.

${ }^{7}$ Liber pontificalis, 3 Bde., ed. Louis Duchesne, Paris $21955-1957$. hier Bd. 2 S. xxxvii.

${ }^{8}$ Die exemplarische retrospektive Quelle: Liber Pontificalis des Boso, Liber pontificalis 3, Duchesne S. \$-\$\$ (ab Gelasius II. 1118 originale Arbeit bis zum Tode des Kardinalpriesters Boso 1178). 
im Glanz des goldenen Zeitalters der Kirchenväter standen. So tat es auch Innozenz II. Nur wenige hatten ältere Namen aufgegriffen, von den Päpsten, die nicht nur Heilige, sondern auch Märtyrer waren, wie Urban II. und gerade noch Calixt II., dem Kardinal Pierleoni sehr nahe stand. Aber Petrus Pierleoni entschied sich für einen der ersten Nachfolger Petri, wie es vor ihm nur Swidger von Bamberg getan hatte als er sich 1046 Clemens II. nannte. Es ging hier um Persönlichkeiten aus apostolischer Zeit, die laut der Überlieferung Petrus, oder Petrus und Paulus, direkt gekannt hatten. ${ }^{9}$ Nicht umsonst gilt Clemens II. als der erste Papst des Reformpapsttums, das damals noch unter der Leitung des deutschen Kaisers stand.

Anaklet, der zu Unrecht von Cletus unterschieden wurde, hatte eine besondere Bedeutung für die Stadt Rom. In der vom Liber Pontificalis erwähnten Geschichte heißt es, dass Anaklet vom Apostel Petrus selbst als Presbyter eingesetzt wurde und Begründer der memoria Petri war, der Gedenkstätte am vatikanischen Hügel, die seit Konstantin der Brennpunkt der Petrusbasilika geworden war. Dort habe er auch eine Grablege für die römischen Bischöfe geschaffen, wo er selber iuxta corpus beati Petri bestattet worden sei. ${ }^{10}$ Obwohl sich nichts hiervon aus historischen oder archäologischen Belegen bestätigen ließ, und die Grablegegeschichte als von den späteren Kompilatoren des Liber Pontificalis erfunden gelten kann, ${ }^{11}$ hat Anaklet I. im 12. Jh. zweifelsohne ein bestimmtes Profil gehabt. Sein Gedenktag wurde am 13. Juli in St. Peter und der Lateranbasilika gefeiert. ${ }^{12}$ Dieser Anaklet war auch einer der vermeintlichen Autoren von gefälschten Papstbriefen römischer Bischöfe aus den ersten Jahrhunderten, die - als Teil der pseudoisidorischen Dekretale - gerade in der Reformbewegung dankbar rezipiert wurden, um die päpstliche Gewalt zu untermauern. ${ }^{13}$ So hat Pierleoni sich von seiner Papstwahl ein Hauptmotiv der Reformbewegung, die Orientierung auf die ecclesia primitiva, in besonderer Form zum Leitfaden gemacht. ${ }^{14}$

Sein kirchenpolitisches Programm hinterließ Anaklet II. in visueller Form im Lateranpalast. In einigen neuen Gemächern im privaten Teil der päpstlichen Residenz waren während der vorangehenden Pontifikate eine Reihe von Wandgemälden angebracht worden, die eine direkte Reflektion der päpstlichen Sicht auf den siegreichen Investiturstreit bildeten. Sie sind nur noch in gezeichneten Kopien späterer Zeit bekannt. Der Papst wurde in seiner Doppelrolle als geistlicher Führer der

\footnotetext{
${ }^{9}$ Vgl. zu Clemens III. (Wibert): Lila YAWN, Clement's New Clothes. The Destruction of Old S. Clemente in Rome, the Eleventh-Century Frescoes, and the Cult of (Anti)Pope Clement III., Reti Medievali Rivista, Italia, 13, Apr. 2012 <http://www.rmojs.unina.it/index.php/rm/article/view/343/423> (9.5.2012), S. 20; ZIESE (wie Anm. 6), S. 92.

${ }^{10}$ Liber Pontificalis 1 DUCHESNE S. 125. Anders als über Cletus wird von Anacletus kein Märtyrertod berichtet. Doch ist die Verehrung als Märtyrer im 12. Jh. üblich: Pierre JounEL, Le culte des saints dans les basiliques du Latran et du Vatican au douzième siècle, Roma 1977, S. 255 (Feiertag 13. Juli, gegen Cletus am 26. April). Vgl. DBV 19, S. 397.

11 Michael Borgolte, Petrusnachfolge und Kaiserimitation. Die Grablegen der Päpste, ihre Genese und Traditionsbildung, Göttingen 1989, ${ }^{2} 1995$, S. 16-20.

12 In den Quellen des 11.und 12. Jhs.: Jounel (wie Anm. 10), S. 137, 199: S. Anacleti, papae et martyris.

${ }^{13}$ Diese Beziehung wird, vielleicht zu einseitig, betont von Herbert BLOCH, Monte Cassino in the Middle Ages. 3 Bde, Roma 1986, S. 966, Anm. 3.

${ }^{14}$ Johannes LAUDAGE, Ad exemplar primitivae ecclesiae, Kurie, Reich und Klerusreform von Urban II. bis Calixt II., in: Stefan WEINFURTER (Hg.), Reformidee und Reformpolitik im spätsalisch-frühstaufischen Reich, (Quellen und Abhandlungen zur Mittelrheinischen Kirchengeschichte 68), Mainz 1992, S. 47-73.
} 
Christenheit präsentiert sowie als oberster Herr aller weltlichen Fürsten im Westen. ${ }^{15}$ Calixt II. hatte eine neue päpstliche Privatkapelle, die dem HI. Nikolaus geweiht wurde, und zwei angrenzende camerae bauen lassen. ${ }^{16}$ In der Freskenausstattung der Kapelle ist Anaklet II. stark hervorgehoben, auch wenn die Konzeption des Programms wohl auf seinen ehemaligen Schutzherrn Calixt zurückgeht. ${ }^{17}$

Das Apsiswandgemälde zeigt die Jungfrau Maria als Himmelskönigin, von zwei Päpsten der frühchristlichen Zeit flankiert: Anaklet I. und Silvester I. ${ }^{18}$ Damit sind petrinische und konstantinische Traditionsstränge zum Ausdruck gebracht. Zu Füßen der Jungfrau knien Calixt II. und Anaklet II. in Proskynesis. Beide haben den rechteckigen Nimbus der in der Gegenwart erkennbaren Personen. Calixt greift mit Silvester auf Konstantin, Anaklet / Petrus mit seinem Namensgeber auf Petrus zurück. Diese Darstellung und die dazugehörige Inschrift machen es wahrscheinlich, dass Anaklet mindestens der Vollender des Freskenzyklus gewesen ist. Die darunterliegende Zone zeigt eine Reihe von siegreichen Investiturstreitspäpsten bis Gelasius II., um den Kapellenpatron Nikolaus von Bari gruppiert, zwischen ihnen die großen frühchristlichen Päpste Leo und Gregor der Große. Alle, auch die rezenten Päpste sind mit dem Heiligennimbus und dem Epitheton sanctus ausgezeichnet. ${ }^{19}$ Die Papstreihe ist damit zwischen 1061 und 1124 vollständig.

Die zeitgenössischen Reformpäpste sahen also ihre Position als tief in der Geschichte des Papsttums verwurzelt, einerseits mit den universalen Kirchenvätern Leo und Gregor als Vorgänger, andererseits auch mit Silvester, der dem Constitutum Constantini zufolge als Ursprung des päpstlichen Anspruches auf weltliche Oberhoheit gelten konnte. Anaklet I. führt die ganze Tradition in die apostolische Zeit zurück und bestätigt gleichzeitig die Legitimität seines Namensvetters. Die Historisierung des Themas wird noch durch das mehrmals beobachtete Detail intensiviert, dass Silvester ein phrygium trägt und sein Pendant Anaklet I. nicht: dem Papst soll die Tiara ja erst von Konstantin verliehen worden sein. ${ }^{20}$ Auf die mögliche Auftraggeberrolle Anaklets II. ist später zurückzukommen.

\section{Anaklet und die römische Liturgie}

\footnotetext{
${ }^{15}$ Richard Krautheimer, Rom. Schicksal einer Stadt 312-1308, Leipzig 1987, S. 170.

${ }^{16}$ LP Boso, S. 378-379; Ingo HERKLOTZ, Die Beratungsräume Calixt' II. im Lateranpalast und ihre Fresken, Kunst und Propaganda am Ende des Investiturstreits, ZKunstG 52 (1989), S. 145-214.

${ }^{17}$ Gerhart B. LADNER, Die Papstbildnisse des Altertums und des Mittelalters. 3 Bde. Città del Vaticano 1941-1970-1984, 1941, S. 192-194, S. 202-218; Ursula NILGEN, Maria Regina - Ein politischer Kultbildtypus?, RJK 19 (1981), S. 1-33, S. 3-7; Ursula NILGEN, Amtsgenealogie und Amtsheiligkeit. Königsund Bischofsreihen in der Kunstpropaganda des Hochmittelalters, in: Katharina BIERBRAUER - Peter KLEIN - Willibald SAUERLÄNDER (Hgg.), Studien zur mittelalterlichen Kunst 800-1250. Festschrift für Florentine Mütherich zum 70. Geburtstag, München 1985, S. 217-234, S. 223-224; BLOCH (wie Anm. 13), S. 964966; HeRKLOtz (wie Anm. 16), S. 212-214; BORGOLte (wie Anm. 11), S. 154-156.

${ }^{18} \mathrm{Vgl}$. Schema des Alfano-Grabmals in S. Maria in Cosmedin mit der Madonna Regina zwischen zwei Engeln und zwei zeitgenössischen Päpsten (Calixt II. und Gelasius II.): LADNER 1941 (wie Anm. 17), S. 251252.

19 Über das Fehlen des Bildnisses von Honorius II.: Borgolte (wie Anm. 11), S. 161 Anm. 64.

${ }^{20}$ Gerhart B. LADNER, Der Ursprung und die mittelalterliche Entwicklung der päpstlichen Tiara, in: Herbert A. CAHN - Erika SIMON (Hgg.), Tainia. Roland Hampe zum 70. Geburtstag 1, 2 Bde., Mainz 1980, S. 449481, S. 455-456.
} 
Bei einer umstrittenen Papstwahl war es besonders wichtig, die zeremonielle Normierung des Rituals genau zu beachten. Am 22. Februar 1130 erfolgte die Papstwahl Pierleonis durch eine Mehrheit des Kardinalkollegiums in der Titelkirche S. Marco. ${ }^{21}$ Die Wahl war in den letzten Jahrzehnten üblicherweise in irgendeiner praktisch verfügbaren Kirche erfolgt. Daher war die Elektion in S. Marco nichts Überraschendes, ebenso wenig wie die gleichzeitige Wahlversammlung für Innozenz im Kloster S. Gregorio Magno. Die Gegner Anaklets betonten jedoch, dass S. Marco sich in unmittelbarer Nähe der Geschlechtertürme der Pierleoni befindet, was so direkt nicht stimmt. Gleich nach dem Wahlausgang wird ein Kardinaldiakon den Gewählten mit dem roten Mantel bekleidet haben - indecenter, so die Gegner - und Pierleoni wird seinen bemerkenswerten Papstnamen bekanntgegeben haben. ${ }^{22}$

Schon am nächsten Tag, einem Sonntag, fand die feierliche Bischofsweihe und Krönung Pierleonis statt, am Ort, der dafür seit vielen Jahrhunderten als praktisch obligat - aber nicht de jure notwendig - und zweifelsohne am aussagekräftigsten galt: die Basilika von St. Peter. Dieses Faktum war umso wichtiger, weil sich Innozenz am gleichen Tage mit der Titelkirche des Haimerich, der Diakonie S. Maria Nova, als Schauplatz der Weihe begnügen musste. Die Kirche am Ostende des Forum Romanum liegt übrigens fast in Sichtweite von S. Marco. Die Anhänger Anaklets beschreiben die Prozession von S. Marco nach St. Peter unter Betonung der getreuen Vollziehung der vorgeschriebenen Strecke entlang der Strassen der via sacra, das heißt der gewohnten Route der päpstlichen Prozession durch das Campo Marzio. ${ }^{23}$ Auch unterstreichen sie die Tatsache, dass Anaklet auf der sacratissima cathedra von St. Peter inthronisiert wurde. Der Beginn des Pontifikats war damit im liturgisch-rituellen Sinne erfolgreich, auch wenn nicht der Kardinal-Bischof von Ostia traditionsgemäß das Weihegebet sprechen konnte, weil dieser zur Gegenpartei gehörte, sondern der Kardinal-Bischof von Porto diese Ehrenaufgabe wahrnahm. ${ }^{24}$ Dieser Petrus Senex war Kardinal seit 1102 und damit das älteste Mitglied des Kollegiums.

Eine wichtige liturgische Aufgabe eines Bischofs, die auch seine Haltung zu konkreten Kirchenbauten zum Ausdruck bringen konnte, war die Kirchweihe. Die dedicatio neuer oder erneuerter Kirchen als Propagandamittel für die Imagepflege eines Pontifikats und als Instrument der Reform erscheint bei den zeitgenössischen

\footnotetext{
${ }^{21}$ Kardinal-Electoren von Innozenz II an König Lothar III. 5.1130, Codex Udalrici no. 352, Watterich 2, S. 182-183: His vero circa horam tertiam rite peractis, Petrus Leonis hora sexta, qua Judea Christum crucifixit et tenebrarum caligo mundo involvit, cum suis conspiratoribus atque consanguineis aliisque manifesto pretio conductis ecclesiam sancti Marci, turribus fratrum propinquam, festinanter adiit, cappam rubeam indecenter induit ficticiaque pontificatus insignia arripuit.

${ }^{22}$ Vgl. zu Paschalis II. 1099: Carlo Servatius, Paschalis II., (1099-1118): Studien zu seiner Person und seiner Politik, (Päpste und Papsttum 14), Stuttgart 1979, S. 35-37; Agostino PARAVICINI BAGLIANI, II corpo del Papa, Torino 1994, S. 119-120.

${ }^{23}$ Brief der Kurie Anaklets an Diego Gelmírez 1130 in Historia Compostellana 3.23.5, S. 457: ...cum honoratorum consensu pari et communi voto dominum Petrum filium Petri Leonis, kardinalem presbiterum tituli sancti Calixti, in Papam Anacletum prestante Domino unanimiter concorditer ac feliciter elegerunt et ad beati Petri apostoli basilicam in hymnis et laudibus, sicut consuetudo Ecclesie est, per viam sacram deduxerunt atque in sacratissimam eius cathedram imponentes secunda dominica Quadragesime [23.2.1130] venerabilis senex Petrus Portuensis episcopus et plures diversarum regionum episcopi eum in Romanum Pontificem ad altare beati Petri celeberrime consecrarunt. Unde secundum antiquam Romani ordinis normam coronata est civitas, letitia fuit in clero, exultatio in populo, miseris et oppressis dulce solamen.

${ }^{24}$ PALUMBo (wie Anm. 2), S. 226-227.
} 
Bischöfen und dem Papst. Unter den Reformpäpsten wird sie seit Urban II. spürbar mit diesen Intentionen ausgeübt. ${ }^{25}$ Der Liber Pontificalis nennt von Paschal II. 20 Weihen: nicht nur frappiert die Anzahl, sondern auch die Novität dieser Erwähnung in den jüngeren Liber Pontificalis-Teilen. ${ }^{26}$ Innozenz II. hat die Gelegenheiten nicht versäumt, während seiner jahrelangen Wanderungen durch West-Europa mehrere Kirchen zu weihen. Die Weihe der Abteikirche Cluny III am 22. Oktober 1130 war davon zweifelsohne die bedeutendste, sowohl im kirchenpolitischen als auch kulturhistorischen Sinne. ${ }^{27}$ Vor ihm hatte Urban II. 1095 schon den Hochaltar der neuen Kirche geweiht; nun ging es um eine Abschlussweihe. Als Innozenz 1132 nach Italien zurückgekehrt war, weihte er S. Pietro in Ciel d'Oro in Pavia, wo der vermeintliche Leichnam des Kirchenvaters Augustin verehrt wurde. ${ }^{28}$

Von Anaklet ist in Rom nur eine Kirchweihinschrift erhalten geblieben neben einer ganzen Reihe weitere Weihinschriften anderer Päpste aus diesen Jahrzehnten des 12. Jahrhunderts. Die Überlieferungsausnahme S. Lorenzo in Lucina wird uns noch weiter beschäftigen, aber es ist kaum vorstellbar, dass Anaklet in den acht Jahren seines Pontifikats keine anderen Kirchweihen vorgenommen hat. Noch eine andere Kirchweihinschrift aus seinem Pontifikat ist allerdings lange erhalten geblieben. Eine Platte aus der kleinen Kirche S. Nicola de Calcarario, im Tempelgebiet des heutigen Largo Argentina, erinnerte an die Weihe der Kirche durch den Kardinalbischof von Porto - es muss sich um Anaklets Bündnispartner Petrus von Porto gehandelt haben im Jahre 1132. ${ }^{29}$ Weihen gehörten zu den Akten, die bei der endgültigen Disqualifikation eines Papstes zum Gegenpapst ihre Rechtskraft verloren. In der Regel wird die Erinnerung getilgt und eventuell durch eine Neuweihe des kanonischen Papstes ersetzt worden sein. ${ }^{30}$ Wir wissen, dass Anaklet im September 1133 in Anagni die Weihe eines Altars für die Reliquien der örtlichen Heiligen Oliva vorgenommen hat. Die Inschrift ist durch Zufall bekannt geblieben, obwohl die Steinplatte im 16. Jahrhundert wohl absichtlich vernichtet wurde. ${ }^{31}$ Baronio berichtet, Anaklet habe, seinen Vorgängern und besonders Calixt II. folgend, viele Altäre in Rom konsekriert. Davon zeugten in seiner Zeit noch etliche Inschriftplatten, die aus Nachlässigkeit der Zerstörung entronnen waren. Baronio persönlich habe sie rückwirkend doch noch beseitigen lassen. ${ }^{32}$ Letzteres könnte mit dem Vorgang in Anagni im Zuge der Gegenreformation übereinstimmen.

Das wirkungsvollste Instrument eines Papstes, die Legitimität seines Amtes zu zeigen, waren seine öffentlichen, rituellen Auftritte in der Stationsliturgie der Stadt

\footnotetext{
${ }^{25}$ Louis I. HAMILTON, A sacred city: consecrating churches and reforming society in Eleventh-century Italy, Manchester - New York 2010, besonders S. 134 ff., $185 \mathrm{ff}$.

${ }^{26}$ LP 2, S. 305 u. Anm. 65.

27 Ordericus HE 13.11, ed. Chibnall Bd 6, S. 418.

${ }^{28}$ PALumbo (wie Anm. 2), S. 469.

${ }^{29}$ Anna BLENNOW, The Latin consecrative inscriptions in prose of churches and altars in Rome 10461263: edition with translations and a commentary on language and palaeography, (Miscellanea della Società Romana di Storia Patria 56), Roma 2011, S. 96-100.

${ }^{30}$ Reordinationen, Wiedertaufen und Wiederweihen von Kirchen waren auch in Reformkreisen umstritten: ZIESE (wie Anm. 6), S. 194.

${ }^{31}$ PALUMBo (wie Anm. 2), S. 430.

32 Baronio, Annales 1130. 49, ed. Bd 18 (1746), S. 451: Sed et imitatione praedecessorum, praesertim vero Callisti secundi, qui plura in Urbe consecravit altaria, ipse voluit eadem laude digna peragere. Dedicata namque legimus Romae nonnulla ab eo \& consecrata fuisse altaria, \& aeditorum incuria servatus adhuc inscriptiones, quas delendas curavimus... Vgl. BLENNow (wie Anm. 29), S. 95-96.
} 
Rom. Das Stationswesen bot die bedeutendste Erlebnisform päpstlicher Präsenz in seiner Bischofsstadt. Der sogenannte Ordo Romanus des vatikanischen Kanonikers Benedikt ist hierfür eine nahezu zeitgenössische Quelle. ${ }^{33}$ Sie wurde kurz nach 1140 aus älterem Material kompiliert mit der offensichtlichen Absicht, die altehrwürdige Tradition der Stationsliturgie sowohl zu bestätigen als sie auch für den aktuellen Gebrauch als Norm zu präsentieren. Das Kalendarium sah ein intensives Programm päpstlicher Auftritte in geschichtsträchtigen Kultbauten und Stadtteilen vor, das natürlich nur in Zeiten der stabilen Präsenz der Kurie wahrgenommen werden konnte.

So erklärt Anaklet in einem Schreiben an Erzbischof Diego Gelmírez von Compostella, dass er 1134 der ältesten Tradition seiner Vorgänger entsprechend im Lateran ruhig und friedlich, würdig und fromm die Feierlichkeiten der Ostertage und des übrigen Kirchenjahres begangen hat, wie das üblich war. ${ }^{34}$ Die Betonung verrät einerseits, dass es so selbstverständlich nicht war, da im letzten Jahr der Rivale Innozenz noch kurz im Lateran geherrscht hatte, andererseits für wie wichtig Anaklet gerade diese in der Tradition verwurzelten liturgischen Auftritte hielt. Tatsächlich sah das in der Ordo Benedikts aufgenommene Stationsprogramm die Vollziehung der Gründonnerstag-, Karfreitags- und Osternachtsfeierlichkeiten im Lateran vor: in der Basilika, teilweise in der Palastkapelle der HI. Laurentius und in der Basilika S. Croce in Gerusalemme. ${ }^{35}$ Die Erwähnung des Laterans dient wohl auch zur Betonung der aktuellen Herrschaft Anaklets in der althergebrachten Residenz des Papstes und der Kurie.

Auf die anderen traditionellen Stationen wird Anaklet nicht verzichtet haben, so lange er ohne Konkurrenz in Rom verblieb. Anaklet hat dabei vielleicht ebensoviel römisch-imperialen Prunk entfaltet wie Innozenz bei seinen Auftritten in St. Denis und Lüttich. ${ }^{36}$ Dort fiel es den Augenzeugen wie Suger auf, wie feierlich und kaiserlich der Papst sich zeigte, aber in Rom war man schon seit Jahrzehnten an diese pompa gewöhnt. Der Papst ritt „mit dem goldbereiften Phyrium als ornamentum imperiale (behütet), auf einem weißen, mit der (roten) Schabracke geschmückten Pferd“ inmitten eines Hofstaates von Kardinälen und Palastbehörden zu den Stationskirchen. ${ }^{37}$ Dies war ganz und gar more romano, und wie Innozenz außerhalb Roms, so wird Anaklet in der Stadt sich dem Zeremoniell gebührend verhalten haben, wie die Römer es erwarteten und wie es einem rechtmäßigen Papst zustand.

\section{Anaklet und die Kirchen Roms}

\footnotetext{
33 Ordo Romanus von Benedictus Canonicus: P. FABRE - L. DuCHESne (Hgg.), Le Liber Censuum de l'Église romaine, 2 Bde, Paris 1910 / 1952, Bd 2, S. 141-164.

${ }^{34}$ Anaklet an Diego Gelmírez 1134, Historia compostellana 3.38.3, S. 488: Sollempnitates paschales antiqua predecessorum nostrorum consuetudine in Lateranensi palatio cum omnibus civitatis nostre patriarchiis eum aliis anni festivitatibus quiete ac pacifice, honorifice ac devote peregimus.

${ }^{35}$ Sible DE BLAAUW, Cultus et decor. Liturgia e architettura nella Roma tardoantica e medievale: Basilica Salvatoris, Sanctae Mariae, Sancti Petri. Città del Vaticano 1994 (Studi e testi della Biblioteca Apostolica Vaticana 355-356), S. 292-308.

${ }^{36}$ Mary StRoLL, Symbols as Power. The Papacy following the Investiture Contest, Leiden - New York Copenhagen 1991, S. 180-181.

37 Zitat von BORGOLTE (wie Anm. 11), S. 161.
} 
Die Quellen behaupten, dass die Anhänger Anaklets St. Peter und weitere Kirchen Roms gleich nach der Papstwahl ausgeraubt und ernsthaft beschädigt hätten. ${ }^{38}$ Tatsächlich hat es zwischen Februar und April 1130 zwischen den beiden Parteien in Rom Kämpfe gegeben, deren Umfang jedoch kaum mehr einzuschätzen ist. ${ }^{39}$ Auch im Juni 1133, als Innozenz sich unter dem Schutz König Lothars III. zeitweilig zur Stadt Rom Zutritt verschaffen konnte, ist es zu gewalttätigen Auseinandersetzungen gekommen. Schaden hat es also bestimmt gegeben, und Fehlverhalten sind den Truppen beider Parteien zuzutrauen, aber es wäre grotesk, der Darstellung Glauben zu schenken, Anaklet sei der Urheber zielgerichteter Plünderungen der römischen Kirchen gewesen. Warum sollte ein geschäftskundiger Papst von unbescholtenem Lebenswandel, der seine Legitimität in seiner Bischofsstadt zu festigen versuchte, die ehrwürdigen Hauptkirchen dieser Stadt, die Bühnen seines öffentlichen Auftretens, als Papst bewusst entehren ${ }^{40}$ Eine Untersuchung der möglichen spezifischen Beziehungen Anaklets zu den Kirchen Roms führt zu einem anderen Ergebnis.

\section{St. Peter}

Als Römer hatte Anaklet eine enge Verbindung zur Grabkirche des Apostelfürsten. Nicht nur trug er den Namen des Apostels, sondern die petrinische Tradition spielte auch im Reformpapsttum eine wesentliche Rolle. Der Gewählte ließ sich nach der Wahl ohne Verzögerung zum Vatikan führen, um ordnungsgemäß dort die Weihe und die Papstkrone zu erhalten. Seine Konsekration zum Bischof am Papstaltar über die confessio Petri und seine Inthronisation auf die sacratissima cathedra in der Apsis von St. Peter waren für die offensichtlich zahlreich vertretene Bürgerschaft Roms augenfällige Zeichen der Legitimität des neuen Papstes. Nach der Messe erhielt Anaklet das päptliche phrygium am dafür üblichen Ort, nämlich auf den Stufen des Torhauses vor St. Peter, alles "nach den Normen der alten römischen ordo". ${ }^{41}$

Während die Anakletianer den ordnungsgemäßen Hergang des ersten Auftretens des Papstes in St. Peter betonen, behaupten die Kardinäle der innozenzianischen Partei dem damals noch neutralen deutschen König Lothar III. gegenüber, dass die Truppen des Petrus Pierleoni die Petersbasilika aller kostbaren, von Päpsten und rechtgläubigen Kaisern geschenkten Objekten beraubt hätten. ${ }^{42} \mathrm{Als}$ das Schisma vorbei war, wurde diese Episode von anderen Autoren übernommen. ${ }^{43} \mathrm{St}$.

\footnotetext{
${ }^{38}$ Die direkteste Quelle: Brief der innozenzianische Kurie: s. unten Anm. 42. Später: LP Boso, S. 380 (hier wird auch S. Maria Maggiore ausdrücklich genannt); Vita Bernardi 2.1, S. 90-91.

39 PALUMBO (wie Anm. 2), S. 229, vgl. S. 298.

${ }^{40}$ Charakteristik der Persönlichkeit Anaklets von G. SCHWAIGER, Lex. MA 1 (1999), S. 568.

${ }^{41}$ Historia Compostellana 3.23.5: oben Anm. 23.

42 Kardinal-Electoren von Innozenz II an König Lothar III. 5.1130, Codex Udalrici no. 352, Watterich 2, 182-183: Sequenti autem die ecclesiam beati Petri armis petiit, machinis circumdedit, tecta murosque fregit, homicidiis peractis et nimia humani sanguinis effusione, sic cum improbis apostolorum principis intravit ianuas. [...] Depredationes vero ecclesiarum et precipue beati Petri thesaurum, quem pontifices Romani et sacratissimi imperatores Deo beatoque Petro dedicaverunt, in lampadibus aureis, calicibus thuribulis, candelabris, imaginibus, crucibus, gemmis aliisque vasis preciosis, nec non et palliis et vestibus sericis auro gemmisque contextis, direptiones nec non et praediorum ecclesiasticorum pignorationes et peregrinorum expoliationes quantae sint, qui Romam vel lerusalem properant euntes et redeuntes, ubique diffamant. Que vero alia turpia ipse suique complices gerant, regalibus auribus non sunt referenda.

${ }^{43}$ LP Boso, S. 380; Chronicon basileense, De BLAAUW 1994 (wie Anm. 35), S. 648. Vgl. Nicola CAMERLENGHI, The life of the Basilica of San Paolo fuori le Mura in Rome: architectural renovations from the ninth to
} 
Peter besaß ohne Zweifel den reichsten Kirchenschatz der Stadt, was die Romplünderer aller Jahrhunderte gewusst haben. Wenn wirklich eine Plünderung stattgefunden hat, kann dies kaum im Sinne Anaklets selbst geschehen sein. Es war vielmehr in seinem Interesse, so bald wie möglich unter korrekten Bedingungen über dem Grabe Petri die Messe zu zelebrieren.

In den ersten Monaten nach der Papstweihe hat Anaklet seine Urkunden immer mit „bei St. Peter" unterschrieben. ${ }^{44}$ Obwohl er über die Residenz des Laterans verfügen konnte und dort auch mitunter war, blieb er offensichtlich regelmäßig in der bescheidenen päpstlichen Wohnstatt bei St. Peter. Die ganze hochliturgische Zeit vom Anfang der Fastenzeit bis zu Pfingsten, wird Anaklet dem Stationskalender getreu mehrmals in St. Peter die Pontifikalgottesdienste zelebriert haben, ebenso auch in den nächsten Jahren. Als Innozenz II. im Juni 1133 mit König Lothar nach Rom zurückkehrte, konnte er Anaklet nicht aus der Engelsburg und der Peterskirche vertreiben. Deshalb musste die Kaiserkrönung unüblicherweise im Lateran stattfinden. ${ }^{45}$

Wir wissen nicht, ob in den Pontifikatsjahren Anaklets Bau- oder Ausstattungsmaßnahmen in der Peterskirche vorgenommen wurden. Die Basilika muss jedenfalls in Würde benutzbar gehalten worden sein. Als Innozenz seit 1138 als einziger Papst in Rom herrschte, war ihm daran gelegen, gleichfalls kostbare Parafernalien für den Hauptaltar der vatikanischen Basilika zu stiften, um die Erneuerungen, die unter Calixt II. vorgenommen worden waren, zu komplettieren und Anaklets Pontifikat im Rückgriff auf den - von beiden geehrten - Calixt zu übergehen. ${ }^{46}$

\section{St. Paul vor den Mauern}

In der großen Apostelbasilika an der Via Ostiense hatte die Familie Pierleoni etwa im Jahre 1128 den Vater des Kardinals Pierleone in einem antiken Sarkophag mit heidnischen Darstellungen bestatten lassen. ${ }^{47}$ Der gigantische Sarkophag wurde oberirdisch im Atrium oder in der Vorhalle der Kirche aufgestellt. Eine derartige Bestattung war im frühen 12. Jahrhundert in Rom wohl nicht sehr üblich. Zwar gab es oberirdische Grabmäler im Eingangsbereich der Kirchen, wie das Alfanusgrabmal in der Vorhalle von S. Maria in Cosmedin, aber für freistehende antike Sarkophage dieser Größe scheint der einzige Präzedenzfall das Grabmal Kaiser Ottos II. im Atrium von St. Peter gewesen zu sein. ${ }^{48}$ Nun ging es um die Grablege des Familienoberhauptes eines Geschlechts, das seit Jahrzehnten zu den treuesten Anhängern des Papsttums gehörte. Die Familie Pierleoni hatte kurz vor der Papstwahl des Kardinals offensichtlich

the nineteenth centuries. Diss. Ph.D. (University Microfilms International, Ann Arbor, Mich.) Princeton 2007, S. 96-97 Anm. 129.

44 Die äußerst lückenhaft überlieferten Bullen Anaklets bei PALUMBO (wie Anm. 2), S. 649-679: vom 24.2.1130 bis zum 29.8.1130 bei S. Peter, außer Lateranum 25.2 und 27.3. Ab dem 27.9.: Benevento.

${ }^{45}$ LP Boso, S. 382. Siehe Anm. 8

46 DBV 56, S. 435-436; De BlaAuw 1994 (wie Anm. 35), S. 648, S. 649-650.

47 PALUMBo, S. 167; GREgORovius 2 (wie Anm. 3), S. 179-180: „....das Mausoleum dieses jüdischen Crassus ..., welchen die Inschrift echt jüdisch als einen durch Reichtum und Kinder unermesslichen Mann ohnegleichen preist".

${ }^{48}$ Sible DE BLAAUW, Die ottonischen Kaisergräber in Magdeburg und Rom: Visualisierung der Herrschermemoria im europäischen Kontext, in: Wolfgang SCHENKLUHN - Andreas WASCHBÜSCH (Hgg.), Der Magdeburger Dom im Europäischen Kontext. Beiträge des internationalen wissenschaftlichen Kolloquiums zum 800-jährigen Domjubiläum in Magdeburg vom 1. bis 4. Oktober 2009. Regensburg 2012, S. 277-290. 
besondere Ansprüche, die sie in einer der wichtigsten Kirchen Roms für alle Kirchenbesucher auffällig visuell zum Ausdruck bringen wollte. Der Vater wurde in einer Inschrift neben dem Grabmal gelobt als Diener des Gesetzes, Zier des Vaterlandes und Liebhaber der Stadt. ${ }^{49}$

Diese Grablege ist nur denkbar, wenn es gute Beziehungen zwischen den Benediktinermönchen von St. Paul und der Familie Pierleoni gegeben hat. ${ }^{50}$ Dabei ist einer der neun Söhne, der Kardinal Petrus, wohl der wichtigste Faktor gewesen. Er war stolz darauf, in seinen französischen Bildungsjahren Mönch in Cluny gewesen zu sein. ${ }^{51}$ Die Paulsabtei war schon seit langer Zeit das Zentrum der Cluniazenser in Rom. ${ }^{52}$ Der Abtei galt eines der ersten Privilegien, die Anaklet in seinem Pontifikat ausstellte. ${ }^{53}$ Übrigens war in St. Paul auch das Gedächtnis Gregors VII. lebendig geblieben, des Onkels des Vaters Pierleoni. Der Name Hildebrands, damals Leiter der Abtei, war an der kostbaren Bronzetür von 1070 noch immer in der Stiftungsinschrift zu lesen. Obgleich die Bezeichnung ,altgregorianisch' für die Gesinnung des Kardinals Petrus wohl nicht sehr distinktiv ist, hat seine Blutsverwandtschaft bestimmt eine besondere Bindung mit dem alten Helden der Reformbewegung erwirkt.

Auch für Innozenz waren die Verbindungen zu den Cluniazensern jedoch von wesentlicher Bedeutung. ${ }^{54}$ Er wusste sich die Unterstützung des Mutterklosters Cluny zu sichern und als er mit Lothar III. 1133 in Rom war, bemühte er sich neben dem Lateran auch St. Paul zum Brückenkopf seiner kurzen Herrschaft in der Stadt zu machen. Nach dem kaiserlichen Abzug war die Wiederinbesitznahme der Lateranbasilika und der Kirche St. Paul für Anaklet ebenso bedeutend. ${ }^{55}$ Obwohl es während des Schismas Spannungen zwischen der anti-anakletischen Stellungnahme der Abtei Cluny und der Affinität desselben Anaklets zu den Cluniazensern gegeben haben muss, scheinen die Benediktinermönche St. Pauls auf der Seite Anaklets gestanden zu haben. ${ }^{56}$

Nach Anaklets Tod wird von einer durchgreifenden Restaurierung der großen Dreikaiserbasilika durch Innozenz II. berichtet. ${ }^{57}$ Doch war Innozenz offensichtlich den Mönchen St. Pauls gegenüber misstrauisch. Deswegen entzog er ihnen das Tochterkloster der Tre Fontane, um dort eine Zisterzienserabtei zu gründen. ${ }^{58}$ Bei der Baukampagne ging es um Reparaturen der enormen Dachkonstruktion, wofür bei Kirchen mit diesen Ausmaßen in Rom traditionell die Baumstämme aus Süditalien

\footnotetext{
${ }^{49}$ [...] Vir fuit immensus, quem proles, gloria, census / Sustulit in vita non sic ut alter ita. / Legum servator, patriae decus, Urbis amator. / Extruxit celsis turribus astra poli. [...] Zitiert nach Ilderonso SCHUSTER, I. La basilica e il monastero di S. Paolo fuori le mura. Note storiche, Torino 1934, S. 93-94.

${ }^{50}$ CAMERLENGH (wie Anm. 44), S. 98-104.

${ }^{51}$ Epist. VIII: Anaklet an Abt Petrus und die Mönche von Cluny 1.5.1130: PALUMBo (wie Anm. 2), S. 652, vgl. ebd., S. 117.

52 SCHUSTER (wie Anm. 50), S. 52-59; S. 92-93.

${ }^{53}$ Epist. V: Anaklet an Abt Anastasius S. Pauli 27.3.1130: PALUMBo (wie Anm. 2), S. 651. Für die guten Beziehungen Anaklets mit der Abtei Montecassino: BLOCH (wie Anm. 13), S. 960-969.

54 MALECZEK (wie Anm. 1), S. 56-57.

${ }^{55}$ Anaklet an Diego Gelmírez 1134, Historia Compostellana 3.38.3, S. 488: Basilicas s. loannis et s. Pauli Apostoli cum quibusdam munitiunculis aliis, quas in adventu Lotharii inimici nostri invaserant et de quibus multum gloriabantur, nuper recepimus et in potestate nostra tenemus.

${ }^{56}$ Drei anakletianische Kardinäle waren Benediktiner: MALECZEK (wie Anm. 1), S. 73.

57 LP Boso, S. 384.

58 Joan BARCLAY LLOYD, SS. Vincenzo e Anastasio at Tre Fontane near Rome: History and architecture of a medieval Cistercian abbey. Kalamazoo 2006, S. 17-21.
} 
geliefert werden mussten. Im Querhaus wurde eine extra Kolonnade aus kostbaren Spolien eingebaut, die den riesigen Raum in der Länge in zwei Zonen aufteilte. Wohl aus statischen Gründen erreichte man hier auch eine Aufteilung der liturgischen und kultischen Funktionen um den Hauptaltar mit dem Apostelgrab herum. Das ganze Projekt wurde später Innozenz zugeschrieben, während die Konstellation stark auf Anaklet als Urheber hinweist. ${ }^{59}$ Außerdem war für die Lieferung der enormen Dachbalken die Allianz Anaklets mit Roger II. von Sizilien, der vom Pierleoni-Papst die Königswürde erlangt hatte, nützlich.

\section{Lateranbasilika}

Die Kardinäle an Innozenz' Seite nennen den Lateran nach St. Peter als Hauptziel der Plünderer. Die Truppen Anaklets sollen mit Rauch und Feuer in die Kirche eingedrungen sein, den Palast besetzt, die päpstlichen Thronstühle beschädigt und die Kapelle Sancta Sanctorum ausgeraubt haben. ${ }^{60}$ Basilika und Palast waren gerade in dieser Zeit Prestigeobjekt des Reformpapsttums, als Zentrum des kurialen Verwaltungswesens und als Kathedrale. Die Basilica Salvatoris, oder Sancti Johannis, war seit Alexander II. die Grabkirche der Reformpäpste gewesen. ${ }^{61}$ Derselbe Anselm von Lucca galt auch als Anreger der vita communis der Kleriker der Basilika. ${ }^{62}$ Seit Calixt II. wurden fünf Päpste in einer Reihe in der Lateranbasilika beigesetzt. Man braucht nicht das Constitutum Constantini anzuführen um zu wissen, dass die Lateranbasilika im 12. Jh. ein reges Interesse des Papsttums genoss auf Grund ihrer Eigenschaften als Gründung des Kaisers Konstantin und als frühchristliche Bischofskirche Roms. ${ }^{63}$ Die dauerhafte Gründung einer Gemeinschaft von Regularkanonikern an der Basilika war eine Leistung der Reformpäpste Paschalis II. und Calixt II. So wurde die Lateranskirche, nicht wie S. Maria Maggiore und St. Peter von Säkularkanonikern betreut, sondern von Geistlichen, die sich einer monastischen Lebensordnung unterwarfen, im Einklang mit den Idealen der gregorianischen Reform. Damit war auch eine beständige spirituelle Totenfürsorge für die beigesetzen Päpste gewährt. ${ }^{64}$ Michael Borgolte hat außerdem die Beziehung zwischen dem Salvatorpatrozinium der Basilika und der neuen Bezeichnung des Papstes als vicarius Christi betont. ${ }^{65}$

Anaklet war nicht wie Honorius II. selber Regularkanoniker gewesen, aber seine Sympathie für diese junge spirituelle Bewegung braucht nicht in Zweifel gezogen zu werden, ebenso wenig übrigens wie die seines Gegners Innozenz. ${ }^{66}$ Jedenfalls gibt es mehrere substantielle Hinweise auf eine tiefgreifende Beschäftigung Anaklets mit der

\footnotetext{
${ }^{59}$ CAMERLENGH (wie Anm. 44), S. 104-109.

60 Kardinal-Electoren von Innozenz II an König Lothar III. 5.1130, Codex Udalrici no. 352, Watterich 2, 182-183: Altera autem die armata manu ad Lateranensem ecclesiam perrexit, fumo, igne, sanguine eam violenter invasit, palacium conscendit, portas confregit, sedes pontificum contrivit, sacrarium beati Laurentii aperuit, quae optima sibi visa sunt diripuit, ad propria se recollegit. Nachträglich ist von Schaden an einem Altar in der Kirche die Rede: DLE, S. 346-347.

61 BORgolte (wie Anm. 11), S. 147-166.

62 De BlaAuw 1994 (wie Anm. 35), S. 208-210.

63 Ebd., S. 203-208.

${ }^{64}$ BORGOLTE (wie Anm. 11), S. 157. Parallele mit dem neue Phänomen der dynastischen, traditionsbildenden 'Grabkirchen' bei den frühen Saliern (Speyer): ebd., S. 156-157.

${ }^{65}$ Ebd., S. 158.

${ }^{66}$ Gegen die einseitige Überbewertung der engen Beziehungen zwischen Innozenz II. und den Regularkanonikern: MALECZEK (wie Anm. 1), S. 41, S. 56.
} 
Architektur der Konstantinsbasilika. Die Diskussion darüber braucht hier keine Wiederholung in extenso. ${ }^{67}$ Es geht um die Vermutung, das große mittelalterliche Querhaus, das nicht zur konstantinischen Bausubstanz gehört, sei im Pontifikat Anaklets entstanden. Die Motive für diese eingreifende Umgestaltung sind manifest: in praktischer Hinsicht mehr Bewegungsraum um den Hauptaltar herum, im ikonologischen Sinne eine Angleichung der Basilika an das frühchristliche Idealmodell Alt St. Peters, zugleich die große Rivalin der Salvatorkirche. Peter Cornelius Claussen hat in seiner jüngsten Monografie zur Lateranbasilika meine früheren Argumente teilweise bestätigt, ist jedoch der Meinung, dass das heutige Querhaus in der Bausubstanz nicht mehr das der dreißiger Jahre des 12. Jhs. ist, sondern einen völligen Neubau Nikolaus IV. um 1290 darstellt. ${ }^{68}$ Die bauhistorischen Beobachtungen scheinen überzeugend, lassen aber die Annahme bestehen, dass das Konzept und die Grundlage des Querhauses aus dem Pontifikat Anaklets stammen.

Nicht eine einzige schriftliche Quelle erinnert an den Bau des Querhauses im 12. Jh., ebenso wenig wie im 13. Jh. Der Schriftsteller des Laterankapitels Johannes Diaconus nennt einige Jahrzehnte nach Anaklet nur in vagen Worten den Ausbau der Kirche unter Innozenz II. ${ }^{69}$ Die Quellen unterstellen nach etwa 1140 jedoch die Existenz des Querhauses in den räumlichen Verhältnissen des Kircheninneren. ${ }^{70}$ Ohne in den Quellen erwähnt zu werden war es da und wurde bald als Originalsubstanz des konstantinischen Baues betrachtet. Ein erfolgreicheres Ergebnis hätte sich der Bauherr kaum denken können: die Lateranbasilika wäre damit schon immer St. Peter und St. Paul vergleichbar gewesen. Die Ehre dieses Eingriffes könnte dem Petrus Pierleoni gebühren. Der Umbau passt genau in seiner Ideologie: die Modellwirkung des frühen Christentums, auch in der Architektur, die Unterstützung der Regularkanoniker und schließlich der Ausbau der Lateranskirche als Herrschaftszentrum und Mausoleum der Reformpäpste. Man könnte Innozenz II. ähnliche Motive zuschreiben, und er wurde tatsächlich nach seinem Tode als Bauherr und Stifter der Kirche gerühmt, in der er sich aufwendig beerdigen ließ. ${ }^{71}$ Bei seinen Maßnahmen ging es um Dachreparaturen, wobei die Balken von seinem ehemaligen Gegner Roger von Sizilien zur Verfügung gestellt wurden, um eine Wiederherstellung des Glockenturmes neben der Fassade, um die Neuweihe einer Kapelle, sowie um die Stiftung kostbarer Altargeräte. ${ }^{72}$ Auffälligerweise schweigt Johannes Diaconus über die größte Baumassnahme dieser Periode, das Querhaus.

Falls Anaklet tatsächlich der Urheber des bedeutungsvollen Umbaus der Lateranbasilika war, ging es im Nachhinein um eine delikate Angelegenheit, die sich jedoch lösen ließ, weil die inhaltlichen Motive der rivalisierenden Parteien des Schismas sehr ähnlich waren und deswegen Verformungspotenzial vorhanden war. Eine selektive Überlieferung, eine Vagheit in der Formulierung und die Verlagerung

\footnotetext{
${ }^{67}$ De BlAAUW 1994 (wie Anm. 35), S. 221-227, S. 230-233; Sible DE BLAAUW, Reception and Renovation of Early Christian Churches in High Medieval Rome, in: Claudia BOLGIA - Rosamond MCKITTERICK - John OSBORNE (Hgg.), Rome Across Time and Space: Cultural Transmission and the Exchange of Ideas, c.5001400. Cambridge 2011, S. 151-166, S. 160-162.

68 Peter Cornelius CLAUSSEN, Die Kirchen der Stadt Rom im Mittelalter 1050-1300, Band 2, (Forschungen zur Kunstgeschichte und christlichen Archäologie 21), Stuttgart 2008, S. 143-157, S. 166-167, S. 170.

${ }^{69}$ DLE, S. 348-349.

70 De BlaAuw 1994 (wie Anm. 35), S. 260-261.

71 DLE, S. 348-349.

72 Für die Pankratiuskapelle s. De BlaAuw 1994 (wie Anm. 35), S. 257-260.
} 
derselben Motive auf die andere Partei konnten die Essenz des Geschehenen aufrecht erhalten, ohne die unterlegene Partei in Erinnerung zu rufen. Ein derartiger historiographischer Vorgang könnte den Äußerungen des Romkenners Gerhoch von Reichersberg zugrunde liegen. Der bayrische Propst nennt 1152 die Lateranskirche zusammen mit den Kirchen S. Croce und S. Maria Nova als Orte, die sowohl im baulichen, als auch im geistlichen Sinne in der jüngsten Vergangenheit „vergrößert“ wurden. ${ }^{73}$ Baulich ist die Umgestaltung samt der Einschiebung eines Querhauses von den beiden letzten Kirchen in diesen Jahren bekannt. Die Aussage wollte hervorheben, dass alle drei Kirchen von den von Gerhoch bewunderten Regularkanonikern von S. Frediano in Lucca betreut wurden. S. Croce ließ der ehemalige Regularkanoniker aus Lucca und Titelkardinal, inzwischen Papst Lucius II (1144-1145), eingreifend erneuern. ${ }^{74}$ In S. Maria Nova hatte Kardinalkanzler Haimerich die Chorherren von S. Frediano eingeführt. ${ }^{75}$ Die umgestaltete Kirche wurde erst 1161 geweiht. ${ }^{76}$ Beide Bauherren waren in der Zeit des Schismas ausgesprochene Gegner Anaklets im Kardinalskollegium gewesen. Gerhoch, der sich eindeutig im gleichen Lager befand, macht ohne ihre Namen zu nennen die Urheber der „Vergrößerung“ des Baus und des geistlichen Lebens an S. Croce und S. Maria Nova direkt erkennbar. Hinsichtlich der Lateranbasilika, die schon ab Anfang des Jahrhunderts von Regularkanonikern betreut wurde, dürften die verantwortlichen Persönlichkeiten für die Leser jedoch nicht mehr identifizierbar gewesen sein. Die materielle Vergrößerung der Lateranbasilika lässt sich indes kaum auf anderes beziehen, als auf eine visuell auffällige Umgestaltung des Kirchenraumes, das heißt auf den Einbau des Querhauses. Papst Anaklet ist sein wahrscheinlichster Erbauer, aber dessen Verdiensten war in der Darlegung Gerhochs keine Rolle zugedacht. Gerhoch steht gleichsam auf der Grenze zwischen kommunikativem und kulturellem Gedächtnis: er überliefert die eigene Erfahrung auf selektive Weise und stiftet damit eine neue, in der kulturellen Überlieferung wurzelnde Erinnerung.

\section{Lateranpalast}

In der Freskenausstattung der Nikolauskapelle des Lateranpalastes befand sich eine Inschrift. Louis Duchesne hat in einer bestechenden Argumentation den im Original schon längst verschollenen Text rekonstruiert:

Sustulit hoc primo templum Calixtus ab imo / vir celebris late Gallorum nobilitate. / Praesul Anacletus papatus culmine fretus / hoc opus ornavit variisque modis decoravit. ${ }^{77}$

Während Calixt II. die Kapelle erbaut hat, hat Anaklet sie ausgestattet und geschmückt, das heißt: vollendet. Damit zeigt Anaklet sich als Universalerbe des Calixt. Der hatte im

\footnotetext{
73 Im an Papst Eugen III. überreichten Traktat über Psalm 64: PL 194, S. 41; Peter CLASSEN, Gerhoch von Reichersberg. Eine Biographie mit einem Anhang über die Quellen, ihre handschriftliche Überlieferung und ihre Chronologie, Wiesbaden 1960, S. 147-148.

74 DLE, S. 347; LP 2, S. 385; Paul F. KEHR, Regesta pontificum Romanorum. Italia Pontificia, 8 Bde., Berlin 1906-1935, Bd. 1, S. 37 Nr. 73; Peter Cornelius CLAUSSEN, Die Kirchen der Stadt Rom im Mittelalter 10501300, Band 1, (Forschungen zur Kunstgeschichte und christlichen Archäologie 20), Stuttgart 2002, S. 418-420.

75 KeHr, Regesta (wie Anm. 75) Bd. 1, S. 65 / 67 Nr. 8; Kehr, Regesta (wie Anm. 75) Bd. 3, S. 428 Nr. 73.

${ }^{76}$ LP Boso, S. 403; CLAUSSEN 2002 (wie Anm. 75), S. 471-472.

77 DUCHESNE, LP 2, S. 325 Anm. 22; Louis DUCHESNE, Le nom d'Anaclet II au palais de Lateran. Mémoires de la Société de Antiquaires de France 5th ser. 9 (1888), S. 197-206.
} 
geheimen Beratungszimmer nebenan den Sieg der Investiturstreitpäpste über die kaiserlichen Gegenpäpste darstellen lassen: Die Letzteren krümmten sich auf dem Boden und dienten als Schemel für die frontal thronenden kanonischen pontifices. ${ }^{78}$

Im Frühjahr 1133 musste Anaklet einige Monate aus der Residenz weichen wegen der Kaiserkrönung Lothars III. durch Innozenz, aber sonst hat er den Lateranpalast wohl als Stützpunkt seiner Regierung regelmäßig benutzt. Obwohl Innozenz ab Oktober 1137 in Rom verblieb, hat er seine Bullen erst am 21.3.1138, zwei Monate nach Pierleonis Tod, im „Lateranum“ abgegeben. ${ }^{79}$ Anaklet war also bis zu seinem Tod praktisch Herr und Gebieter im Lateran. In der Nikolauskapelle zeigte er sich in dieser Rolle, prominent als zeitgenössischer Auftraggeber, aber gleichzeitig im geschichtlichen Zusammenhang des Reformpapsttums. In den Worten Herbert Blochs: "With a rare forcefulness Anacletus has here set a monument to the past to which he himself belonged as its last representative." 80

Aus den späteren Berichten über die Kapelle und aus den Nachzeichnungen der Apsismalerei wird ersichtlich, dass der Name der auf der rechten Seite knienden Stifterfigur sowie seine Erwähnung in der Inschrift schon lange nicht mehr lesbar gewesen waren. Duchesne hat sie zwar überzeugend rekonstruiert, aber ihre Unlesbarkeit war natürlich kein Zufall. ${ }^{81}$ Für die direkten Nachfolger war die Präsenz des ,Gegenpapstes' an dieser Stelle und in diesem bedeutungsvollen Bildzusammenhang unerträglich. Innozenz II. hat sich, sofort nachdem er ins Lateran eingezogen war, gerade um diese Räume gekümmert. Dem Vorbild des Calixt folgend ließ er direkt an der Nikolauskapelle zwei neue Räume einrichten und diese mit einem politischen Bildprogramm ausschmücken. ${ }^{82}$ Die Kapellenapsis hat er dabei natürlich nicht unverändert gelassen.

\section{S. Lorenzo in Lucina}

In der frühchristlichen Titelkirche S. Lorenzo in Lucina, die im 12. Jh. mehrmals renoviert worden ist und eine ungewöhnlich grosse Anzahl von Weihinschriften bewahrt hat, ist das einzige epigraphische Zeugnis des Pierleoni-Pontifikats erhalten. Es geht um eine Platte, welche die Weihe des Hauptaltars im Jahre 1130 durch Anacletus secundus papa memoriert. ${ }^{83}$ Der Papst führte die Weihe "mit eigenen Händen" durch und legte dabei wichtige Reliquien des heiligen Laurentius nieder. Die Beziehungen zu den anderen erhaltenen Weihinschriften des 12. Jhs. sind kompliziert, die Hypothesen zahlreich. ${ }^{84}$ Eine davon lautet, dass man das Andenken an die Weihe durch einen Gegenpapst durch eine nachträgliche Inschrift auslöschen wollte, mit einem gefälschten Text, welche die Weihe in die Zeit Paschalis II. (1112) rückdatiert. ${ }^{85}$ Seltsamerweise befindet sich die letzte Inschrift auf der Rücklehne des Papstthrones in der Apis. In unserem Rahmen zählt jedoch vor allem, dass Anaklets Auftreten gerade

\footnotetext{
78 LADNER 1941 (wie Anm. 17), S. 195-201.

79 PALUMBo (wie Anm. 2), S. 585.

${ }^{80}$ BLOCH (wie Anm. 13), S. 966.

81 DUCHESNE 1888 (wie Anm. 78); die weitere Literatur siehe oben Anm. 17.

82 LADNER 1941 (wie Anm. 17), S. 17-25; Stroll 1991 (wie Anm. 36), S. 188-192.

83 BLENNOW (wie Anm. 29), S. 92-96.

${ }^{84}$ Peter Cornelius CLAUSSEN, Die Kirchen der Stadt Rom im Mittelalter 1050-1300, Band 3, (Forschungen zur Kunstgeschichte und christlichen Archäologie 22), Stuttgart 2010, S. 278-282; S. 290-295.

${ }^{85}$ Francesco GANDOLFO, Reimpiego di sculture antiche nei troni papali del XII secolo, APARA-R 47 (1976),

S. 203-218, S. 211-217.
} 
nicht ausgelöscht wurde. Die Inschrift ist bis heute in der Vorhalle für jeden Besucher lesbar, auch wenn sie mit den anderen Inschriften zusammen ziemlich akkumulativ und verwirrend wirkt. Offensichtlich wollten die verantwortlichen Geistlichen der Kirche nach dem Schisma nicht auf die Erwähnung der kostbaren Reliquien in der Inschrift verzichten.

Die Kirchweihe fand im Mai 1130 nur wenige Monate, nachdem Anaklet auf den Stuhl Petri gewählt wurde, statt. Dies macht es unwahrscheinlich, dass er mit Bauarbeiten in S. Lorenzo in Lucina etwas zu tun hatte. Die Hypothese, dass er als Bauherr mit dem Kirchenmodell im gemalten Bildprogramm der Apsis dargestellt - und nachher in eine Heiligenfigur umgeformt - wurde, ist auch aus anderen Gründen unglaubhaft. ${ }^{86}$

\section{S. Maria in Trastevere}

Der vollständige Neubau der frühchristlichen Titelkirche S. Maria in Trastevere ist eines der anspruchvollsten Bauprojekte Roms im Hochmittelalter und wird üblicherweise Innozenz II. als Bauherr zugesprochen, da er sich im Apsismosaik groß als solcher hat abbilden lassen. Außerdem war er ein Sproß des alten Papareschi-Geschlechts aus Trastevere. Doch waren auch die Pierleoni traditionell in Trastevere ansässig, und Anaklet war vor seiner Papstwahl Kardinalpriester dieser Kirche gewesen.

Mit S. Crisogono bildet die Marienkirche einen Neuaufbruch in der hochmittelalterlichen Kirchenarchitektur Roms. Größer und ,klassischer'-frühchristlich als die vorgehende Generation der Kirchenneubauten wie S. Clemente, zeichnen sie sich durch ein Querhaus, durch architravierte Säulenreihen statt Arkaden und durch die kostbarsten Spoliensäulen und Kapitelle aus. „Ihre üppige Ausstattung lässt einen reichen Stifter vermuten", bemerkt Krautheimer. ${ }^{87}$ In der Literatur wird der Neubau meistens als ein Werk von Papst Innozenz gesehen, um die Erinnerung an die Titelkirche seines Widersachers durch einen glänzenden Neubau zu übertrumpfen. ${ }^{88}$ Ein anderes Szenario erscheint jedoch plausibler, nämlich, dass Papst Anaklet der Initiator des großangelegten Neubaus seiner ehemaligen Titelkirche war, und Innozenz sich entschloss, den Bau samt der Dekoration zu vollenden und sich beim Abschluss im Jahre 1143 als Bauherr der gesamten Kirche darzustellen. ${ }^{89}$ Nicht undenkbar ist sogar, dass Anaklet die neue Kirche noch persönlich geweiht hat, da eine Kirchweihe von Innozenz II. nicht überliefert ist. ${ }^{90}$

Das Apsismosaik feiert den angeblichen Stifter dem traditionellen frühchristlichen Bildschema gemäß als stehende Figur, die Reihe von Heiligen

\footnotetext{
${ }^{86}$ CLAUSSEN 2010 (wie Anm. 85), S. 299-302, mit einer Spätdatierung der Malerei um die Mitte des 13. Jhs.

87 KRAUTHEIMER (wie Anm. 15), S. 183.

88 Stroll 1987 (wie Anm. 2), S. 125-127.

${ }^{89}$ KRAUTHEIMER (wie Anm. 15), S. 183: Die Kirche ersetzt einen Bau des 4. / 9. Jhs. „mag in den zwanziger Jahren des 12. Jhs. möglicherweise von ihrem Titularkardinal Pietro Pierleone... begonnnen worden sein. " Dale KINNEY, S. Maria in Trastevere from its founding to 1215. Diss. New York 1975, S. 199-221, sieht eher Innozenz als Bauherr, der den Stempel der Pierleoni in Trastevere auslöschen wollte. 90 Über die ungewöhnliche Kirchweihgeschichte von S. Maria in Trastevere im Hochmittelalter s. Bernhard SCHIMMELPFENNIG, Ein Text zur Kirchweihe von S. Maria in Trastevere, in: Nicolas Bock et al. (Hgg.), Kunst und Liturgie im Mittelalter, (Römisches Jahrbuch der Bibliotheca Hertziana 33.1999/2000, Beiheft), München 2000, S. 39-45.
} 
maßstabgerecht abschließend, mit einem Modell der neuen Kirche in den Händen. ${ }^{91}$ Völlig innovativ ist jedoch das Zentrum der Komposition. Christus sitzt zusammen mit seiner königlich geschmückten Braut auf einem Gemmenthron. Kitzinger, Nilgen, Wolf und andere haben die Darstellung der Braut ekklesiologisch verstehen wollen: der Maria-Regina-Typus, der auch in der Nikolauskapelle erscheint, ist für die Reformpäpsten Sinnbild der Kirche. ${ }^{92}$ In diesem Sinne schließt sich Innozenz sowohl Calixt II. als auch dem verdammten Anaklet an. Die Inschrift enthält dabei ein persönliches Element: „Als der alte Bau einzustürzen drohte, erneuerte ihn der von hier stammende Papst Innozenz II. “93

\section{Sonstige Kirchen}

Auch von anderen Kirchen lässt sich Anaklet als Stifter oder zumindest als offizieller Auftraggeber vermuten. Doch ist der hypothetische Bestandteil der Annahme größer als in den vorhergehenden Fällen. ${ }^{94} \mathrm{~S}$. Bartolomeo in Isola liegt auf der Tiberinsel, die im frühen 12. Jh. eine Festung der Pierleoni war. Die alte Kirche, eine bescheidene Gründung Ottos III. für die Adalberts- und Batholomäusreliquien, wich in der ersten Hälfte des 12. Jhs. einem Neubau. Die Basilika kann grob datiert werden, aber jeder Beleg eines Stifters, eines Bauherren oder einer Kirchweihe fehlt. ${ }^{95}$ Fest steht, dass Anaklet der Kirche Privilegien und Indulgenzen verliehen hat, was häufig aus Anlass einer Kirchweihe stattfand. ${ }^{96}$ Auch die Renovierung des frühmittelalterlichen Baus von S. Cecilia in Trastevere weist auf das dritte oder vierte Jahrzehnt des 12. Jhs. hin, ohne explizites Zeugnis. ${ }^{97}$ Einige der von Innozenz II. in den ersten Jahren nach seiner Rückkehr nach Rom vorgenommenen Kirchweihen dürften ebenfalls auf Bauprojekte unter Anaklet zurückzuführen sein. Es geht freilich um sekundäre, nicht auf das Stationswesen bezogene Kirchen: S. Tommaso in Parione im Jahr $1139^{98}$ und SS. Michele e Magno 1141, beide als kleine, dreischiffige Säulenbasiliken neu gebaut. ${ }^{99}$

\section{Erinnerungsstrategie unter Innozenz II.}

Als Innozenz sich nach Anaklets Tod in der ganzen Stadt durchsetzen konnte, trat er sofort in seiner vollen päpstlichen Würde mit Prozessionen von Kirche zu Kirche in

\footnotetext{
${ }^{91}$ LADNER 1941 (wie Anm. 17), S. 9-16; Dale KINNEY, The apse mosaic of Santa Maria in Trastevere, in: Elizabeth SEARS (Hg.), Reading medieval images, Ann Arbor 2002, S. 19-26.

92 NILGEN 1981 (wie Anm. 17), S. 24-30; Gerhard WoLf, Salus populi romani. Die Geschichte römischer Kultbilder im Mittelalter, Weinheim 1990, S. 122-123, S. 128.

93 NILGEN 1981 (wie Anm. 17), S. 26: cum moles ruitura vetus foret hinc oriundus / Innocentius hanc renovavit papa secundus.

${ }^{94}$ Vgl. auch S. Clemente: Mary STROLL, Symbols as Power. The Papacy following the Investiture Contest, Leiden - New York - Copenhagen 1991, S. 118-131; CLAUSSEN 2002 (wie Anm. 75), S. 342-343 Anm. 172. ${ }_{95}$ Claussen 2002 (wie Anm. 75), S. 136-137, S. 146-149; Claussen 2008 (wie Anm. 69), S. 13.

${ }^{96}$ PALUMBO (wie Anm. 2), S. 674-675: Epist. LX (1133/1134).

${ }_{97}$ CLAUSSEn 2002 (wie Anm. 75), S. 238-242, S. 247-248: Kreuzgang, Portikus und Turm, sowie Erneuerung des Hauptaltares; CLAUSSEN 2008 (wie Anm. 69), S. 13 über einen möglichen Zusammenhang mit der Etablierung eines Regularkapitels.

${ }^{98}$ BLENNOW (wie Anm. 29), S. 100-104.

99 Blennow (wie Anm. 29), S. 105-110; Martino Muskens, Santi Michele e Magno dei Frisoni. Roma 1993, S. 78-79.
} 
Erscheinung. Ob es sich um demonstrative Kavalkaden handelte oder um reguläre Stationsprozessionen, ist aus den Quellen nicht ersichtlich. ${ }^{100}$ Letzteres ist wahrscheinlicher, denn eine der kräftigsten Legitimierungsinstrumente des römischen Bischofs war gerade das Stationswesen. Der Stationskalender der Fastenzeit bot dem Papst reichlich Möglichkeiten, schon im Frühjahr 1138 in zahlreichen Kirchen der Stadt aufzutreten. In denselben Rahmen gehört sein Bestreben, sich als Stifter für den Bau, die Restaurierung und Ausschmückung der Kirchen einzusetzen. ${ }^{101}$

Ohne Zweifel erstrebte Innozenz eine restlose Diskreditierung seines Rivalen. Das zweite Laterankonzil im Jahre 1139 wurde zu einer posthumen Vendetta gegen Anaklet. ${ }^{102}$ Alle Akte Anaklets wurden aufgehoben, König Roger nochmals gebannt und angesehene Kardinäle, die einst Anaklet unterstützt hatten, als Schismatiker und Häretiker zutiefst erniedrigt. ${ }^{103}$ Letzteres wurde auch von den Zeitgenossen als persönliche Rache des Papareschi-Papstes gegenüber dem ,Vorgänger' erkannt. Innozenz kontrollierte nun die Medien und setzte die Kirchen und Denkmäler Roms als Kommunikationsstrategie zur Konsolidierung seines Pontifikats ein. Er ließ bei der Nikolauskapelle im Lateran zwei neue Räume hinzufügen. Ikonographisch komplettierte die von inm verordnete Ausmalung das bestehende Programm, indem sie Szenen der Kaiserkrönung Lothars im Lateran 1133 darstellte. Die Inschrift nennt den Kaiser als Vasall des Papstes und in der Szene ist Lothar kniend vor dem thronenden Papst abgebildet. ${ }^{104}$ Die reichen Schenkungen kostbarer liturgischer Utensilien an unter Anaklet angeblich geplünderte Kirchen werden in den Chroniken plakativ erwähnt. ${ }^{105}$ Der Geschichtsschreiber Boso verzeichnet in seiner Kontinuation des Liber Pontificalis in der besten Tradition der päpstlichen Gesten die Kirchenrestaurierungen des Innozenz, oder schreibt sie ihm wenigstens zu: S. Maria in Trastevere (totam innovavit et construxit), die Lateranbasilika (tectum resarcivit), St. Paul (tectum resarcivit / constructo super columnis marmoreis muro), S. Stefano Rotondo (reparavit) und die beiden Palastaulen im Lateran (a fundamento construxit). ${ }^{106}$ Die Zahl der zwei von Innozenz überlieferten Kirchweihen ist erstaunlich bescheiden und bezieht sich auf ziemlich unbedeutende Kirchen, die möglicherweise unter Anaklet gebaut worden waren. Umso mehr, so scheint es, war dem ,legitimen' Papst daran gelegen, sie persönlich in der Gesellschaft prominenter Kardinäle demonstrativ zu konsekrieren.

Die päpstliche Fürsorge für die römischen Kirchen, die mindestens teilweise unter Anaklet gut betreut und gepflegt worden waren, nimmt unter Innozenz die Züge der Kompensation und Aneignung an. ${ }^{107}$ In den meisten Fällen reichte es wohl, die Erinnerung an den Verdammten mit einer Gegenerinnerung zu überschreiben.

\footnotetext{
100 Vita Bernardi 2.47, S. 123.

${ }^{101} \mathrm{Vgl}$. Stroll 1991 (wie Anm. 95), S. 180-192.

102 PAlumbo (wie Anm. 2), S. 592; SPRENGer (wie Anm. 5), S. 38-41.

${ }^{103}$ LP Boso, S. 383: Ad hec ordinationes factas a Petro Leonis et aliis scismaticis et hereticis evacuamus et irritas esse censemus (= canon 30 ).

${ }^{104}$ Die politischen Folgen dieser Bilddeutung bei Barbarossa: BORGOLTE (wie Anm. 11), S. 163.

105 LP Boso, S. 380.

106 LP Boso, S. 384. Über Boso's anti-anakletianische Voreingenommenheit CAMERLENGHI (wie Anm. 44), S. 95-98.

107 Vita Bernardi 2.48, S. 124: Dato tempore Innocentius ecclesiae ruinas restaurat, recolligit exsules, ecclesiis antiqua servitia, depopulatas colonias expulsis restituit et insuper congrua dona largitur per singulos.
} 
Manchmal, wie im Falle von Abbildungen (Lateranpalast) oder Inschriften, war eine bewusste Tilgung notwendig. Von Schismatikern konsekrierte Altäre konnten sogar abgerissen werden, wie es hier und da mit Altären geschah, die von Anaklet geweihten Bischöfen konsekriert worden waren. ${ }^{108}$ Mehrere Inschriftenplatten blieben trotzdem in römischen Kirchen erhalten, offensichtlich, weil die Erinnerung an die Weihe und an die Reliquienrekondierung wichtiger war als der Name des ausführenden Papstes. Doch ist unwahrscheinlich, dass eine größere Zahl noch die puristische Sanierung der Gegenreformation erreicht hat, wie Baronio suggeriert. ${ }^{109}$

Gelungen ist die Erinnerungslöschung jedenfalls bei der Totenmemoria des Anaklet. Als typischer Reformpapst mit umstrittener Rechtmäßigkeit war Anaklet wohl am meisten an einer Grablege in der Lateranbasilika interessiert. Im südlichen Teil der Basilika befanden sich unter anderen die Gräber Paschals II. und Calixts II. ${ }^{110}$ Das Grab Anaklets könnte in dieser Reihe wie im Fresko des angrenzenden Palastes eine posthume Rechtfertigung dargestellt haben. Es kam anders: positiv ist über Anaklets Bestattung nichts bekannt. Doch scheinen sowohl die vatikanische Basilika als auch der Lateran bis zum Ende unter der Kontrolle des Pierleoni geblieben zu sein. ${ }^{111}$ Negativ besagen die innozenzianischen Quellen, dass die Brüder Anaklets den Leichnam heimlich bestattet haben, damit die Feinde ihn nicht finden konnten. ${ }^{112}$ Damit wäre auch die delikate Verantwortung der Sieger für den Grabesfrieden und das Gebetsgedenken eines Verstorbenen gelöst. ${ }^{113}$ Demgegenüber setzt Innozenz eine demonstrative Antithese. Er selbst habe veranlasst, im imperialen Porphyrsarkophag des Kaisers Hadrian beigesetzt zu werden. Damit schuf er eine unerhörte Innovation in der päpstlichen Grablegetradition. Der Sarg wurde gleichsam als Prunkstück oberirdisch im Mittelschiff der Lateranbasilika aufgestellt. ${ }^{114}$ Die imitatio imperii stand jetzt im Reformprogramm auf gleicher Ebene mit dem Ideal der ecclesia primitiva. Die Regularkanoniker vom Lateran mögen sich allerdings darüber bewusst gewesen sein, dass der Porphyrsarg mit dem apostolischen Leben wenig zu tun hatte. ${ }^{115}$ Doch dürfte Anaklet auch in dieser Hinsicht nicht viel anders als Innozenz gehandelt haben. In der Grablege seines Vaters in der Benediktinerabtei St. Paul hatte die Pierleonifamilie schon einen Präzedenzfall einer ungewöhnlich monumentalen Grablege geschaffen.

Die Gegenpäpste durften aber nicht vollständig vergessen werden. Sie sollten alleine schon in der Erinnerung bleiben um die von Gott gegebene Macht des kanonischen Papstes als Sieg des Guten über das Böse profilieren zu können. ${ }^{116}$ So findet man in den Schriftquellen bis in die Tradition Baronios eine höchst negative Stilisierung Anaklets mit den topoi des Gegenpapstes. Die als Schemel dienenden Antipäpste im Beratungszimmer Calixt II. im Lateran illustrieren die negative Erinnerung dieser Art am

\footnotetext{
108 PALUMBo (wie Anm. 2), S. 593.

${ }^{109}$ Siehe oben, Anm. 32.

${ }^{110}$ Borgolte (wie Anm. 11), S. 148-149, S. 152; De BlaAuw 1994 (wie Anm. 35), S. 258, S. 260-261.

111 PALUMBo (wie Anm 2), S. 585.

112 LP Boso, S. 383; Ordericus HE 6.13.25; Vita Bernardi 2.47, S. 123: Miserabili pompa corpus eius effertur, cadaver eius in latebris sepelitur, et usque hodie fovea illa a catholicis ignoratur.

${ }^{113} \mathrm{Vgl}$. SPRENGER (wie Anm. 5), S. 42-45.

${ }^{114}$ BORGOLTE (wie Anm. 11), S. 163-165.

115 Zu den beiden Hauptmotiven des Reformpapsttums: Giovanni Mıccoll, Ecclesiae primitiva forma, SM 1 (1960), S. 470-498; LAUdAGE 1992 (wie Anm. 14).

${ }^{116}$ SPRENGER (wie Anm. 5), bes. S. 41-42.
} 
besten. Direkte Erinnerungstilgung war nur dort erforderlich, wo sonst eine positive Rezeption denkbar gewesen wäre: am Grab und wohl auch bei den päpstlichen Beiträgen zu Ehren des Hauses Gottes. Für Anaklet als Mäzen römischer Kirchen war deswegen nach 1138 kein Platz mehr. Seine Stiftungen waren unlösbare Teile des Baubestandes wichtiger Kirchen und hatten funktionalen Zweck in Gegenwart und Zukunft. Sie wurden weiterbenutzt und waren in dem Sinne, gute Werke'. Gerade in diesen Umständen musste der Name des Stifters für immer unsichtbar gemacht werden.

Sible de Blaauw

Radboud University Nijmegen, Institute for Historical, Literary and Cultural Studies 